\title{
The Analysis of Engineering Data Information System Based on Knowledge Management and Internet plus Technology
}

\author{
Nian Lv1,a, Xuan Zhang ${ }^{2}$ \\ ${ }^{1}$ Shandong electric power T\&T engineering company, road No. 1000, Huaiyin District, Ji'nan City, Shandong Province, China \\ ${ }^{2}$ Shandong province training center of construction technology development \\ a570227019@qq.com
}

\begin{abstract}
Adopted information classification and coding technology, the author try to write the WBS code of electric power transformation project and study on the content and form of engineering data. Taking advantage of Internet plus technology, the management information system which conform to the reality of electric power transformation can be developed. Adopted knowledge management theory, we could make use of knowledge to direct movement through the change from information into knowledge.
\end{abstract}

\section{Introduction}

Currently, power net construction has become the main direction of the power construction in China. However, the archive management to the construction data of electric power transformation does not have a unified standard. The requirements of different clients vary. And the project units are lack of instructive document to the classification, arrangement and encode of electric power transformation, which lead to the disorder and nonstandard of construction data filling. Then, there are lots of problem appeared when the project be checked and accepted. Therefore, the management of the data of electric power transformation and the collection, classification, storage, transformation and usage of data are an essential problem for electric power engineering enterprises. The research and study on the contruation data management of electric power transformation would have good influence on the enhancement of management level of electric power transformation projects.

Shandong electric power Transformation Company adopted information classification and encoding technology and encode the WBS code of electric power transformation. Based on WBS code, they studied on the content, form and filling instruction. Through conclusion, classification and encoding, they created code content and wrote down filling indication and example of every forms. Then, with the direction of the theory of management information system, taking advantage of information and Internet technology, the computer management information system which conform to the reality of electric power transformation been developed.

It is different from general computer management information system of construction data. First of all, it is a management information system based on the classification and arrangement of construction data, which makes its functions become more suitable for the reality of the management of electric power transformation and more useful. Secondly, the system connect construction teams, project department, branch companies with head quarter closely, which eliminated isolation and made communication and exchange freely. Finally, it adopted knowledge management and Internet plus technology, which make this system become more advanced and reasonable. From information to knowledge which could direct decision making and movement, and from movement to profit, it improved the technology of this system.

\section{Specific Method}

\subsection{Adopted line classification to classify and encode construction data}

Information classification and encoding refer to the scientific classification of information and then encode data. This method could gather information with same features and tell the information different. And it could encode data with symbol system which could be recognized and dealt with by people or computer

\subsection{The application of WBS structure could decompose the project and make the project scientific}

WBS can decompose the program via its structural features and is convenient to manage the complicated engineer in scale, as well makes it easy to assess and make a conclusion. Compiling the WBS code of it is an 
important task when managing and studying the execution materials. Due to the existing differences amid engineering decomposition in the construction between computing part and program department, it can go on with the study based on the classified methods in respect of program (tech, quality branches), which is aimed at the real situation of Power transmission industry as well as the study of engineering material management. Using the information coding tech, a classic power line of an engineer WBS codes is as below:

\section{A preparation}

$\mathrm{B}$ retesting and locating

\section{C basic program}

$\mathrm{C} / 01$ classified pits $\mathrm{C} / 02$ basic pits to be dug $\mathrm{c} / 03$ transmission of materials $\mathrm{c} / 04$ basic cushions $\mathrm{C} / 05$ basic module $\mathrm{C} / 06$ basic casting $\mathrm{C} / 07$ basic backfill

\section{Tower engineering}

$\mathrm{D} / 01$ basic leveling $\mathrm{D} / 02$ counting material in division $\mathrm{D} / 03$ decomposing the tower $\mathrm{D} / 04$ bolt-on

E ground connection program

E/01 digging and connecting ditches E/02 laying ground connector E/03 installing downlead E/04 welding ground connector E/05ground backfill E/06 ground resistance wave measurement

\section{F stringing work}

$\mathrm{F} / 01$ preparation $\mathrm{F} / 02$ ground connector transportation $\mathrm{F} / 03$ setting up crossing structure $\mathrm{F} / 04$ laying leading rope F/05laying ground connectors F/06 Anchor Line F/07tight string F/08 accessory installation F/08.01spacing bars $F / 08.02$ cable clamp installation F/08.03 Spark gap adjustment F/08.04 Shock hammer F/08.05heavy hammer

\section{G Optical Cable Engineering}

G/01 Fiber optic cable full plate test G/02 laying leading rope G/03 laying the optical cable G/04 accessory installation $\mathrm{G} / 05$ optical fiber cable jointing $\mathrm{H}$ Maintenance and repair

\subsection{Combining various material resources, completing material sorting and studying task}

According to WBS codes, in the course of processing, it collects the useful data inside and outside our province, the necessary tables which must be filled up by the State Grid Corporation, and the Supervision of tabular involving the construction. Besides, the integrated management system, recording and forms of Shandong power transmission Engineering Corporation are also concluded. Consequently, though those forms and recording are used by the enterprise itself, they are a valuable record for the management of the project department.

\subsection{Constructing knowledge management system of transmission and distribution project in Shandong Province with the use of knowledge management theory}

Knowledge management is the new stage of the development of information management, and it is also the extension and development of information management. Knowledge management is a series of question and answer sequence that is the collection of solutions to search for and recognize the key information related to questions, and draw the information to form the specialized knowledge to one question as the basis of decision. In the society of information and knowledge, information, knowledge and some special skills are the tools to gain profits. Knowledge management transform information to knowledge, and guide decisions into practice via knowledge, thus translate acts to profits.

\subsection{Conducting data mining with engineering data management system, thus providing basis for decision.}

The transmission and distribution project in Shandong Province is a temporary project, new knowledge created by the project members only exists in the minds of certain people or project members, few of the knowledge can be stored in the organization. When the task is completed, the knowledge will be distributed among the various departments, and once the individuals or groups who master the key knowledge leave the enterprises, the knowledge chain of the enterprises will be interrupted. Therefore, it is not suitable for the project department to use and spread the knowledge during the transmission and distribution continuously and extensively, which is not conducive to the accumulation of corporate knowledge. Therefore, we need to use the engineering data management system to integrate and mine all the engineering data of project department. Data Mining refers to the process of automatic analysis and extraction of the implicit and previously unknown knowledge that people are interested in and potentially useful for policy makers from a large database or data warehouse. Data mining is the key supporting technology of knowledge management, it is an inevitable process in which data rises to knowledge. Knowledge management system owns the ability to manage and collaborate the knowledge base, and knowledge management processes can also be seen as the mining and use of knowledge. After the combination with data mining techniques, the 
value of the entire knowledge management system is reflected by the knowledge discovery and learning. Through data mining, by using the engineering data of every project, the red flag and high-quality engineering data can be formed and updated. And we can mine the quality, safety and other data through engineering data to provide a base for the project management of transmission and distribution project in Shandong Province.

\subsection{Building database of the transmission and distribution project in Shandong Province to realize big data of engineering materials}

Establishing database of transmission and distribution project in Shandong Province, and realizing replication capacity of projects gradually. The accumulation of many projects benefits the extraction of files of the same type, when facing with the similar project, new project can be created via information platform to make replication capacity to be possible; At the same time, the accumulation of many projects can help new or inexperienced employees find their positions in engineering data management system quickly, and work according to standards of work flow is beneficial to the cultivation of talents.

\section{Application Achievements}

\subsection{Engineering data system cut down the cost of data management}

Engineering data system change the situation of personnel on-site inspection and management, which can cut down large amount of labor costs, vehicle costs and unnecessary food costs, and improve working efficiency greatly, reducing rework cost of materials as well. The cost of every inspection of each project need RMB30004000 at least just from the points of food, live, transport and labour. The cost of data organization, rework of every project needs 5000-10000. In one enterprise, there are 80 transmission and distribution projects annually, and inspects projects every quarter, more than 1.5 million direct benefits can be saved annually...

\subsection{Engineering data management system improves the level of projects management}

The system connects construction materials of corporation headquarters, division headquarters, projects, construction team via internet, thus related leaders, managers can see the real materials to know the schedule, quality, safety situation in time, which will also improve management efficiency. The management of construction materials in the past was at will and false, and memoirs were made usually, which can be changed. The update of materials should be synchronize with construction, so the confidence of construction materials can be improved. The precontrol before construction, the supervision during construction, the retrospect after construction can make engineering data reveal the level of project management actually.

The application of engineering data management platform reveals the improvement of the management of engineering data, and strengthen the security, quality, schedule of projects at a deeper level. This system adapts the trend of the industry of transmission and distribution, and realizes the information management construction materials, thus make sure the standardized and complete of engineering data management, and improve the efficiency and quality to meet the demand of the development of project management. The system improve the depth, vigor, and speed of the project management of transmission and distribution, so greater management benefits and social benefits can be realized.

\subsection{Use the engineering data management system to strengthen knowledge transfer and sharing}

A mature enterprise must be convenient for the employees to inspire and communicate with each other in transformation and sharing of knowledge. The engineering data management system of transmission and distribution project in Shandong Province is beneficial to internal members to learn from each other, communication with and share knowledge with each other; to the knowledge communication between enterprise and the external organizations; to the horizontal exchange of knowledge among all sectors of the knowledge transformation; to the knowledge integration in various areas. The communication not only happens between internal employees, departments, but also should take place among the enterprise, the owner and the supervisor.

\subsection{Use the engineering data management system is in favor of the depth of the knowledge updating}

Setting this system enables all the projects and departments of transmission and distribution project in Shandong Province to exchange their knowledge so that the latest knowledge of the outside world is able to quickly enter the enterprise and be aware of the employees, and the knowledge owned by enterprises and employees can be deepen and updated in the internal and external communication and cooperation.

\subsection{The engineering data management system improves the enterprise's ability to adapt to the environment.s in favor of the depth of the knowledge updating}

The engineering data management system enables the electricity transmission and transformation in Shandong 
Province to keep its vibrant during the "Adapt to the correct rehabilitation" process, and keep high organizational efficiency to respond swiftly to the external uncertainties and dynamic nature.

\subsection{The engineering data management system improves the teamwork spirits of the employees}

Since the engineering data management system need to involve a variety of people and activities, we must rely on the cooperation between the employees leading to the successful completion of engineering data management. Companies, branches, all levels of the project department need to participate in the process of engineering data management altogether to improve the team spirit of employees and enhance the competitiveness of enterprises.

\subsection{Lay solid foundation for the creation of good projects}

In the national high quality awards on-site review, experts speak highly of DaiZong 500kv transformer substation with engineering data management and South HaMi-Zhengzhou $\pm 800 \mathrm{kv}$ high-tension line. DaiZong 500kv transformer substation wins 2014-2015 national high quality award, South HaMi-Zhengzhou $\pm 800 \mathrm{kv}$ hightension line wins 2014-2015 national high quality gold award.

\section{References}

1. Maryam Alavi; Dorothy E.Leidner; Deng wen quan, Knowledge management and knowledge management systems: conceptual foundations and research topics, Management World, 2012-05-15.

2. Dai bibo, Research on performance evaluation of knowledge management in enterprise ERP, Journal of Harbin Engineering University, 2012-04-01.

3. Yan haibin, Chen caiyin, Preparation and optimization management of engineering data, Architecture Technology, 2010-06-15

4. Liu jinxing, Application of improved WBS method in engineering project management, Construction Economy, 2011-06-05

5. Xu zhibin, Design and implementation of engineering data management subsystem, Journal of Jilin University, 2011-05-01.

6. WANG Dong ying, Application of Digital Archives in Engineering Management, Electric Power Constructionty, 2001-01

7. Xu zong wei, Gai su xia, Research on the key success factors and management strategies of knowledge management in Chinese Enterprises, Management World, 2012-03. 